Casa de experimentos: preguntas y transformaciones recientes del Museo de la Solidaridad Salvador Allende y su integración a la comunidad del Barrio República

Casa de experimentos: questões e transformações recentes do Museu da Solidariedade Salvador Allende e sua integração à comunidade do Bairro República

Casa de experimentos: Questions and Recent Transformations of the Salvador Allende Solidarity Museum and Its Integration into the Community of the Republic Neighborhood

\begin{abstract}
RESUMEN: La actual recuperación de los lazos y principios que motivaron al Museo de la Solidaridad desde su gestación en 1971 fue reposicionada a partir de la concepción de para-laboratorio y del valor de la participación colectiva en el pasado y en el presente. Este texto busca dar a conocer el proyecto Mirada de barrio y las resonancias que actúan al interior y exterior del museo. A partir de los distintos procesos de la participación activa y colectiva con las vecinas y vecinos del Barrio República, sector donde se emplaza el museo, se enfatizan las metodologías utilizadas provenientes de los campos de la mediación y la curaduría participativa, además de los giros, preguntas y transformaciones en torno a los compromisos que el proyecto suscita en el museo y en una incipiente comunidad barrial.
\end{abstract}

PALABRAS CLAVE: museo; curaduría; participación; barrio; comunidad

\footnotetext{
* Soledad García Saavedra é historiadora de arte (Universidade do Chile), curadora (Goldsmiths College, Universidade de Londres) e coordenadora de Programas Públicos do Museu da Solidariedade Salvador Allende, Santiago do Chile. 
RESUMO: A recuperação atual dos vínculos e princípios que motivaram o Museu da Solidariedade, desde sua criação em 1971 foi reposicionada a partir da concepção de paralaboratório e do valor da participação coletiva no passado e no presente. Este texto procura apresentar o projeto do bairro Mirada e as ressonâncias que atuam dentro e fora do museu. Dos diferentes processos de participação ativa e coletiva com os vizinhos do Bairro República, o setor onde o museu está localizado, enfatizam-se as metodologias utilizadas nos campos de mediação e curadoria participativa, bem como as transferências de recursos financeiros, questões e transformações em torno dos compromissos que o projeto desperta no museu e em uma comunidade incipiente de bairro.

PALAVRAS-CHAVE: museu; curadoria; participação; bairro; comunidade

ABSTRACT: The current recovery of ties and principles that motivated the Museum of Solidarity since its inception in 1971 was repositioned from the conception of para-laboratory and the value of collective participation in the past and in the present. This text seeks to publicize the Mirada neighborhood project and the resonances that act inside and outside the museum. From the different processes of active and collective participation with the neighbors of the Republic District, the sector where the museum is located, the methodologies used from the fields of mediation and participatory curatorship are emphasized, as well as the money transfers, questions and transformations around the commitments that the project arouses in the museum and in an incipient neighborhood community.

KEYWORDS: museum; curatorship; participation; neighborhood; community

Como citar: SAAVEDRA, Soledad García. Casa de experimentos: preguntas y transformaciones recientes del Museo de la Solidaridad Salvador Allende y su integración a la comunidad del Barrio República. Poiésis, Niterói, v. 20, n. 33, p. 257-276, jan./jun. 2019.

doi: http://dx.doi.org/10.22409/poiesis.2033.257-276

Poiésis, Niterói, v. 20, n. 33, jan./jun. 2019. 


\section{Casa de experimentos: preguntas y transformaciones recientes del Museo de la Solidaridad Salvador Allende y su integración a la comunidad del Barrio República}

El marco modernista que da referencias a los museos y a las practicas curatoriales, entendidas esencialmente como la investigación y producción de exhibiciones basadas en objetos y pensamientos artísticos que contribuyan a la contemplación por parte de un público y a un discurso controlado en su recepción, constituye uno de los paradigmas desafiantes a la hora de involucrar a públicos específicos y no asiduos al arte. El siguiente texto reúne algunas de las experiencias llevadas a cabo en la investigación-acción Mirada de Barrio, desarrollado por el área de Programas públicos del Museo de la Solidaridad Salvador Allende en Santiago de Chile que nutren un campo de observación, cuestionamiento y acción ante las contradicciones y tensiones inherentes cuando una institución museal estrecha lazos con su comunidad vecinal. 
La investigación se comenzó a realizar el 2017 a partir de un replanteamiento del museo de reconstruir su historia artística y social: investigar los lazos de solidaridad que se sostuvieron a nivel internacional desde los años 1970 en adelante y actualizar, mediante la acción, los principios que fundan al museo de "estar al servicio del pueblo" ${ }^{1}$. Esta consigna, declarada en la etapa inicial de su fundación en 1971, ha resonado en la gestión y reflexión interna del equipo del museo en estos últimos años, gatillando preguntas sobre cómo abrir el patrimonio material (infraestructura, colecciones y exposiciones) e inmaterial (memorias, saberes e interpretaciones) del museo a un público diverso. Asimismo, ¿cómo conectar las trayectorias de las obras y exposiciones con las experiencias y conocimientos de las personas?, ¿cómo generar una cercanía del museo con su entorno y un sentido de pertenencia en la vida de los habitantes en una porción de la ciudad de Santiago? En estas preguntas subyacen replanteamientos para las practicas curatoriales. Por una parte, reevaluar los principios modernistas que mantienen una autoridad de conocimiento y por tanto una separación entre objeto y sujeto, o pasado y presente. Por otra parte, implican una búsqueda por flexibilizar las estructuras museales, planificar desde la incertidumbre de los procesos junto a un grupo de personas, abrirse a ejercicios con resultados indeterminados e indefinidos.

Si bien, estas interrogantes se empalman también con el enfoque participativo y dialogante que propone la corriente de la museología crítica, las búsquedas de este proyecto de investigación-acción han estado ligadas al estudio de los giros museales y enfoques de comunidad durante la larga década de los 1960 en América Latina y en particular en Chile. El Museo de la Solidaridad emergió en el seno del clima revolucionario del proyecto socialista de la Unidad Popular del presidente Salvador Allende, donde la participación residió en un medio que intentó diluir las jerarquías epistémicas de las instituciones del arte, las barreras y los cánones del museo, con el propósito de integrar al pueblo. Con la convicción de revertir la cosificación del objeto artístico, la exclusividad elitista del museo y las reglas modernas de colonialismo subordinado al capitalismo corporativo, el Museo de la Solidaridad constituyó un modelo inédito al reunir donaciones de obras de artistas del mundo para el acceso del pueblo chileno. Insertado en un ambiente de arraigo local y po-

Poiésis, Niterói, v. 20, n. 33, jan./jun. 2019. 
pular que brotó con fuerza en los años 1960, el museo surge en una coyuntura artística donde existió un interés por generar instancias de participación a través de exposiciones o foros entre artistas, estudiantes, intelectuales y obreros al interior o fuera del museo, en la calle ${ }^{2}$. Es en ese contexto de preguntas compartidas de cómo movilizar, entender y aterrizar el arte frente a los compromisos con el socialismo y ejercer una revolución social (BIANCHI, 2013, p. 112) es que un grupo de críticos de arte ${ }^{3}$, entre ellos, Mário Pedrosa (1900-1981), encabezó la concepción de un museo plural y democrático, determinado por dos categorías: arte moderno y experimental. Con la experiencia en la dirección del Museo de Arte Moderno y en la sexta Bienal de Sao Paulo en 1961, Pedrosa delineó la función del museo de arte moderno como una "casa de experimentos" o como un "paralaboratorio" (FERREIRA; HERKENHOFF, 2015, p. 142), en el entendido de un ilimitado derecho a investigar $y$, por sobre todo, de experimentar e inventar. Para ejemplificar el enunciado de este fenómeno del arte contemporáneo, Pedrosa recurrió a una comparación entre el espacio y la pintura: "cuando el rectángulo de la tela pierde sus limitaciones regulares y las leyes descubiertas en el espacio del montaje son olvidadas, es claro que la consecuencia es el pintor en la transición a un sin sentido, creando cosas en el espacio real". (p. 143) Con un tono premonitorio, esta descripción aclaratoria de Pedrosa explicaba un estado de transformación de la función del arte al interior del espacio museal durante los años 1960: la disolución de la concepción tradicional del objeto artístico y sus preceptos del montaje, por la posibilidad leer, explorar, imaginar y activar otras creaciones impensadas, intuitivas, desconocidas tanto adentro como afuera del museo. Asimismo, la concepción de para-laboratorio de Pedrosa se podría enlazar a una reflexión sobre la naturaleza ideológica del museo y las fuerzas de hegemonía en la actualidad, mediante la propuesta de la educadora y curadora Nora Sternfeld, quien acuña la posición "paramuseal"/"para-institucional" del museo como una constante interrogación y deconstrucción de sus funciones con el fin de emancipar las lógicas de dominación creando alternativas de conocimiento y experiencias. (STERNFELD, 2017, p. 180) De esta manera, posicionar el campo de investigación-acción en el MSSA significa, por un lado, reconectar con actitudes, ideas, modos y procesos colaborativos que estuvieron inmersos en su gestación a inicios de los años 1970 y que quedó truncado con el golpe de Estado de 1973 - por 
ejemplo, ante la pregunta de ¿cómo conectarnos y replantear una casa de experimentos desde el arte y la comunidad barrial del museo? -, y por otro lado ser conscientes de la realidad opuesta que socialmente circunscribe y permea al museo hoy.

En ese sentido, la construcción de un mundo común que irradió el proyecto socialista en el museo en sus inicios discrepa de la actual realidad neoliberal impuesta en el país, luego de la dictadura militar. La ruptura autoritaria con ese pasado repercute aun en las formas de habitar y convivir en la ciudad. La formación, gestión y autogestión comunitaria en el ámbito cultural fueron suprimidas y desarticuladas (DE LA MAZA, 2010, p. 82), y la segregación territorial se consolidó, debilitando también la cohesión social. (MÁRQUEZ, 2008) A contra corriente de estas condiciones, el proyecto Mirada de barrio optó por reconstruir las relaciones y sus intensidades que afectan a las vecinas y vecinos residentes y transeúntes que habitan diaria o semanalmente en el barrio. Simultáneamente, se buscó transformar el estado desvinculante, derribar gradualmente las barreras de separación entre el museo y las y los vecinos, y crear en conjunto otras alternativas para convivir en el barrio.

\section{Transformaciones recientes en el barrio}

EI MSSA se encuentra hace trece años en una casa palaciega ubicada en la Avenida República (Fig. 1), una de las arterias principales del barrio cuya impronta arquitectónica patrimonial (modelo inglés de barrio-jardín de fines del siglo XIX) alberga hoy un dinámico clima de estudiantes universitarios, comerciantes y trabajadores de fundaciones ${ }^{4}$. La llegada del museo al barrio correspondió a la ubicación de fundaciones, en este caso la Fundación Arte y Solidaridad, por mejorar los estados de destrucción, desmantelamiento y abandono de las casonas en los 2000. El plan mayor de la Municipalidad de Santiago consistió en un cambio de "piel", donde las casonas fueron adquiridas y rehabilitadas por una variedad de instituciones para sustituir el pasado brutal cuando fueron ocupadas como centros de detención y tortura por la Dirección de Inteligencia Nacional (DINA) de la Junta Militar durante la dictadura (1973-1990), y arreglar el daño causado por el terremoto de $1985^{5}$. Recordada por los vecinos como una avenida triste y oscura, con ventanas y mu-

Poiésis, Niterói, v. 20, n. 33, jan./jun. 2019. 


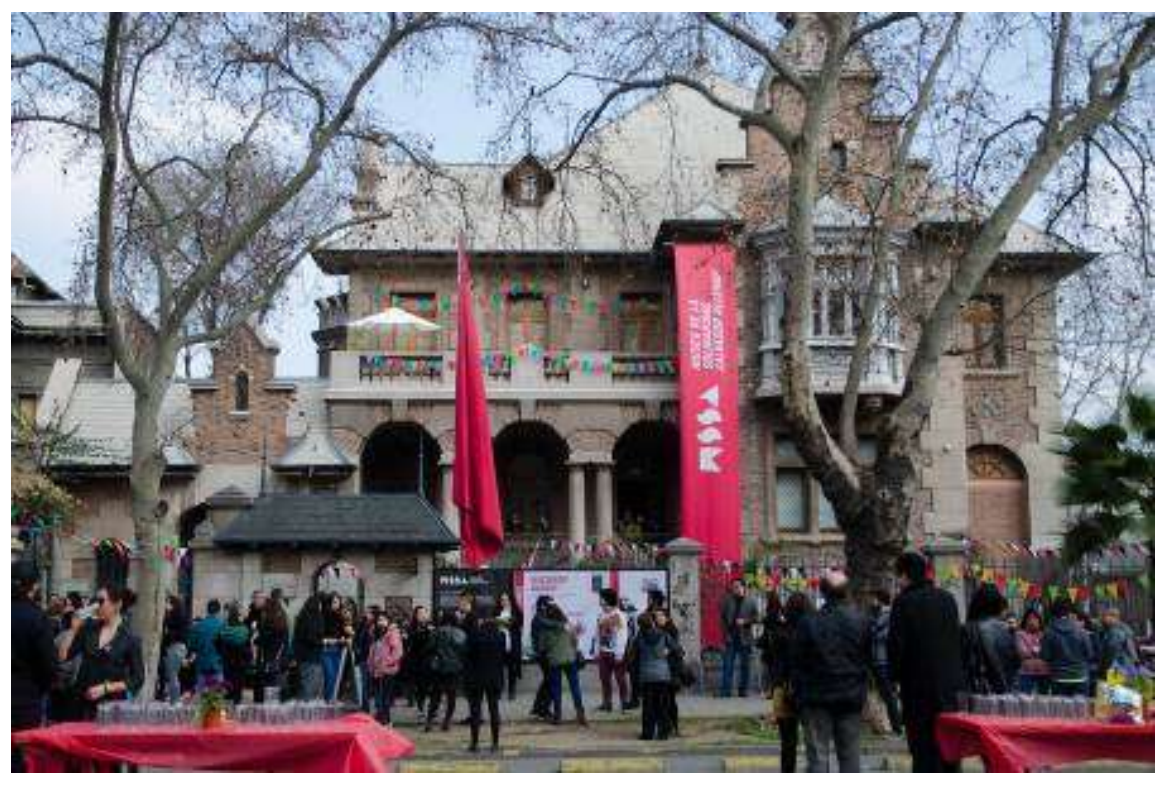

Fiq. 1 - Fachada del Museo de la Solidaridad Salvador Allende en Avenida República, Santiaqo de Chile, 2018.

Poiésis, Niterói, v. 20, n. 33, jan./jun. 2019. 
ros tapiados durante los 1980, la avenida y la única área verde del barrio, la Plaza Manuel Rodriguez, comenzaron a ser remodeladas a partir de los años 1990 con un fuerte impulso de transformar su carácter trágico. Las memorias negativas y los desastres que afectaron las infraestructuras de la avenida fueron restituidas por el resguardo físico de las casonas, al ser declarada Zona Típica el año 1992, y por la nueva vitalidad estudiantil cuando se organiza el Barrio Universitario a partir de 2003. (DRACOS, 2003)

En estos últimos diez años se han gestado iniciativas barriales, como la Junta de Vecinos y los Comites de Patrimonio; las casonas han sido adquiridas por centros culturales autogestionados, como la Corporación Arteduca o el Gran Circo Teatro. Sin embargo, aun los procesos para establecer lugares de encuentro, redes de colaboración o gestar programas colectivos son incipientes ${ }^{6}$. Esta transformación reciente a nivel local, con corte y sutura de sus lazos sociales, va acompañada de una dinámica global y tecnológica de comunicación virtual (redes sociales) que facilita la información y las convocatorias, pero que, en su dimensión física, impide las relaciones cara a cara. Estas dificultades de vinculación - irreconocibles al iniciar el proyecto Mirada de barrio - generó varios desafíos en los modos de conducir las comunicaciones, las tácticas de convocatorias o invitaciones, y los procesos de mediación con los vecinos para introducir el quehacer del proyecto y del museo.

\section{Procesos y metodologías Mirada de barrio}

Uno de los objetivos que nos autoimpusimos al iniciar el proyecto fue el de realizar una curaduría participativa con una selección de la colección del MSSA. Compuesta por más de 2700 obras de arte moderno y contemporáneo procedentes de distintas donaciones de artistas en el mundo (desde 1972 a la fecha), la colección constituye el patrimonio del museo y la fuente para la cuela se ideó un puente de unión con el "pueblo". Como medio de comunicación, la curaduría participativa redefine los sentidos de una colección al romper con las jerarquías entre la alta y la baja cultura (DELISS, 2014, p. 34), integrando a personas que no necesariamente tienen un conocimiento sobre las obras y estableciendo un involucramiento en el diseño, concepción y ejecución de una exposición, posibilitando decisiones y aperturas colectivas. En esa lógica, al momento de diseñar los propósitos de

Poiésis, Niterói, v. 20, n. 33, jan./jun. 2019. 
la investigación-acción y postular a fondos concursables nacionales (Fondart) ${ }^{7}$, pensamos que un medio para acercar a las vecinas y vecinos era el conducir las conversaciones hacia las experiencias y contenidos de algunas obras de la colección y, desde esa base, crear una exposición que tuviera resonancias en la vida del barrio República. Sin embargo, y aun cuando fueron adjudicados favorablemente los fondos para iniciar la investigación, en el transcurso del proyecto fuimos conscientes que los planes y propósitos no encajaban o eran inadecuados al escuchar a las vecinas y vecinos sus impresiones sobre el museo, y sus relatos que se desprendían del habitar cotidiano en el barrio República. Existía un universo paralelo entre el interior del museo y el exterior del barrio. De esta manera, a medio camino del proyecto, decidimos descartar el uso de la colección y abocarnos a una exposición del barrio República para conocernos, compartir y coimplicarnos en la vida común de un territorio y encarnar el propósito que define al museo: la solidaridad.

Las señales de este giro temático, surgieron al momento de ejecutar el programa de $M i$ rada de Barrio durante el año 2017, donde diseñamos y realizamos una encuesta barrial y seis encuentros (Fig. 2 y 3). La encuesta nos ofreció luces sobre la percepción que tenían las vecinas y vecinos del museo y nos permitió tomar varias decisiones sobre las necesidades comunicacionales y metodológicas para poder revertir sus reticencias. Con una muestra final de 318 encuestados realizadas por el equipo del proyecto, participando los profesionales de las distintas áreas del museo, además de la colaboración de estudiantes y voluntarios, los resultados arrojaron que los vecinos desconocían la misión y trabajo del MSSA y lo asociaban más a un museo histórico (70\%) que a uno de arte (29\%). Esto podría explicarse por el nombre del museo, su fuerte relación a la figura de Salvador Allende y la inexistencia del apelativo arte. Estas impresiones de los vecinos evidenciaron hacia nosotros la tarea de comunicar verbal (en la calle - puerta a puerta, esquinas, cafés, plaza - y en los encuentros al interior y exterior del museo) y gráficamente (invitaciones y pendones en el frontis y en la Avenida República) la necesidad de explicitar, gradualmente, la colección de arte internacional, y enfatizar la creación y la experimentación artística contemporánea. Además, nos hizo reconocer que la casona de inicios del siglo XX que alberga 


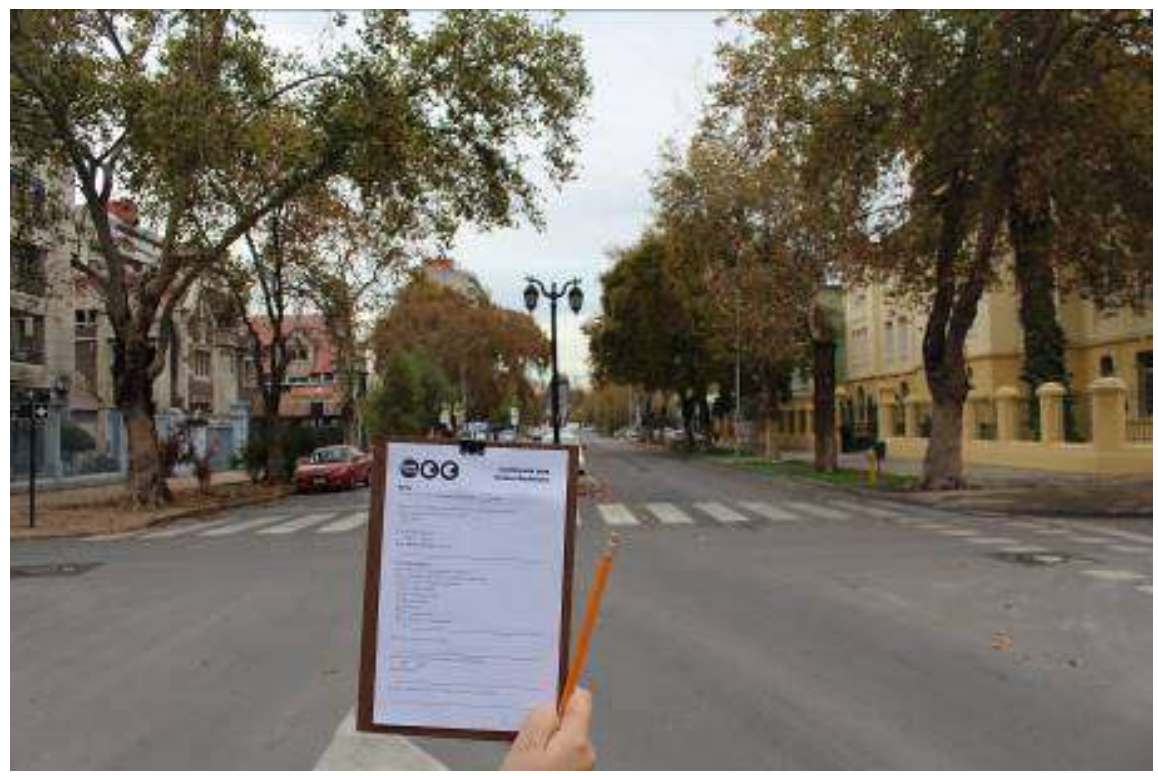

Fiq. 2 - Encuesta barrial, Museo de la Solidaridad Salvador Allende, 2017.

Poiésis, Niterói, v. 20, n. 33, jan./jun. 2019. 


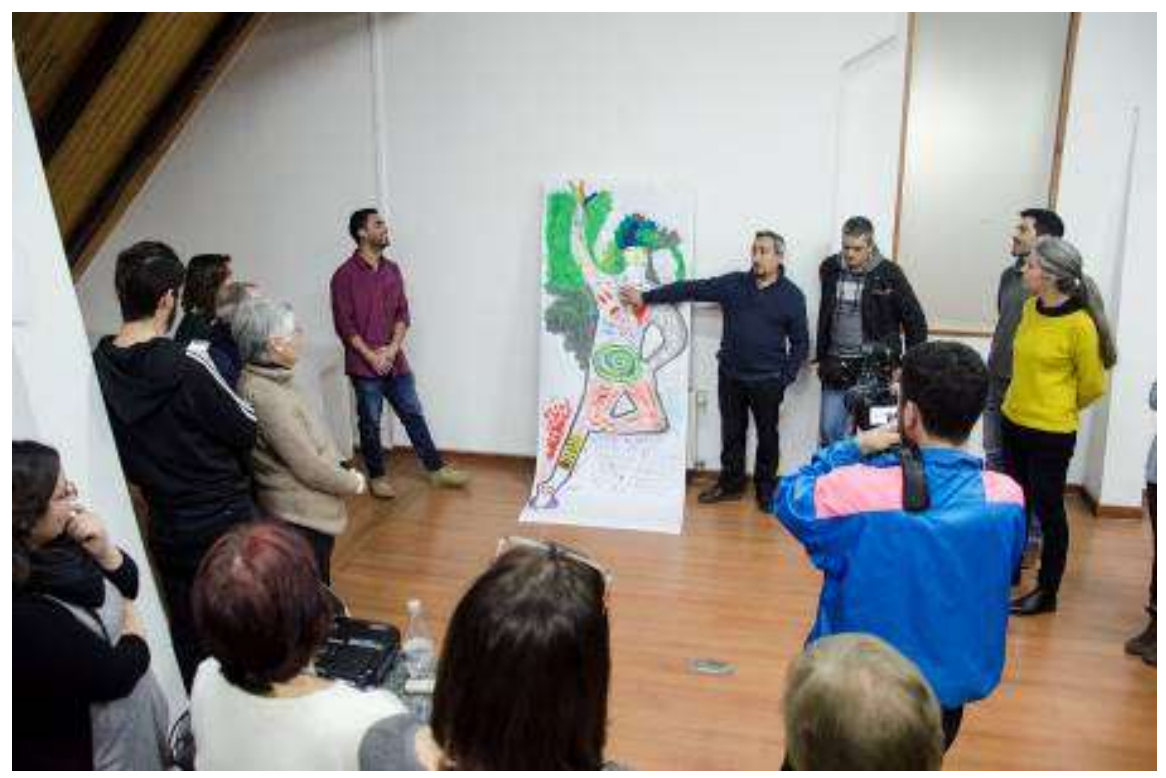

Fiq. 3 - Encuentro vecinal. Mapa corporal del barrio, Museo de la Solidaridad Salvador Allende, 2017.

Poiésis, Niterói, v. 20, n. 33, jan./jun. 2019. 
al museo (ex-Palacio Heiremanns) constituye una barrera simbólica y física que impide el acceso fluido e inmediato, ya sea por su protección (rejas y guardia), solemnidad arquitectónica, o por los recuerdos recientes del pasado (dictadura). Esta distancia con la infraestructura del museo y la desarticulación del barrio repercutió en el reconocimiento de que trabajar con la colección podría haber sido un brinco involuntario sin haber construido, primero, el camino y un colchón para caer y permanecer en grupo. Es decir, necesitábamos construir puentes, aligerar los accesos y facilitar el encuentro de una futura comunidad entre el museo y el barrio, antes de centrarnos, en el corazón del museo, su colección.

La tarea de dar a conocer la colección y exposiciones en el museo, fue reforzada en cada uno de los seis encuentros, no solo a través de las presentaciones que realizamos para introducir las escuchas mutuas entre el museo y las vecinas y vecinos, sino que indirectamente a través de cada una de las sesiones que prepararmos. Aplicamos estrategias pedagógicas del "aprender haciendo" (DEWEY, 1998, p. 72) y metodologías de mediación con énfasis en la creación experimental por medio de las activaciones del cuerpo (el habla, la voz, la escucha, los movimientos, la expresión corporal, la imaginería, la escritura, el dibujo). Al momento de redireccionar la exposición sobre el barrio, los encuentros basados en la conversación y la escucha, fueron modificados, por el hacer. Así, comenzamos el año 2018, realizando un encuentro para dar a conocer los talleres de cocreación en las técnicas de escritura y publicación experimental, intervención fotográfica, textil comunitario y arte postal para niñas y niños (Fig. 4). Las piezas producidas en los talleres, individuales y colectivas, fueron posteriormente exhibidas en las salas del museo, junto con el diseño de distintos mapeos colectivos realizados especialmente para el barrio por el colectivo Iconoclasistas, un documental, una sala de experiencias para ejercitar libremente distintas técnicas y una sala "archivo" con los procesos metodológicas de la investigación (Fig. 5).

La elección de los tipos de talleres se definió a partir de los oficios, practicas e intereses de los propios vecinos. Los procesos y elaboraciones colectivas de estos talleres, fueron facilitados por profesionales ${ }^{8}$ en donde se integraron participantes de distintas generacio-

Poiésis, Niterói, v. 20, n. 33, jan./jun. 2019. 


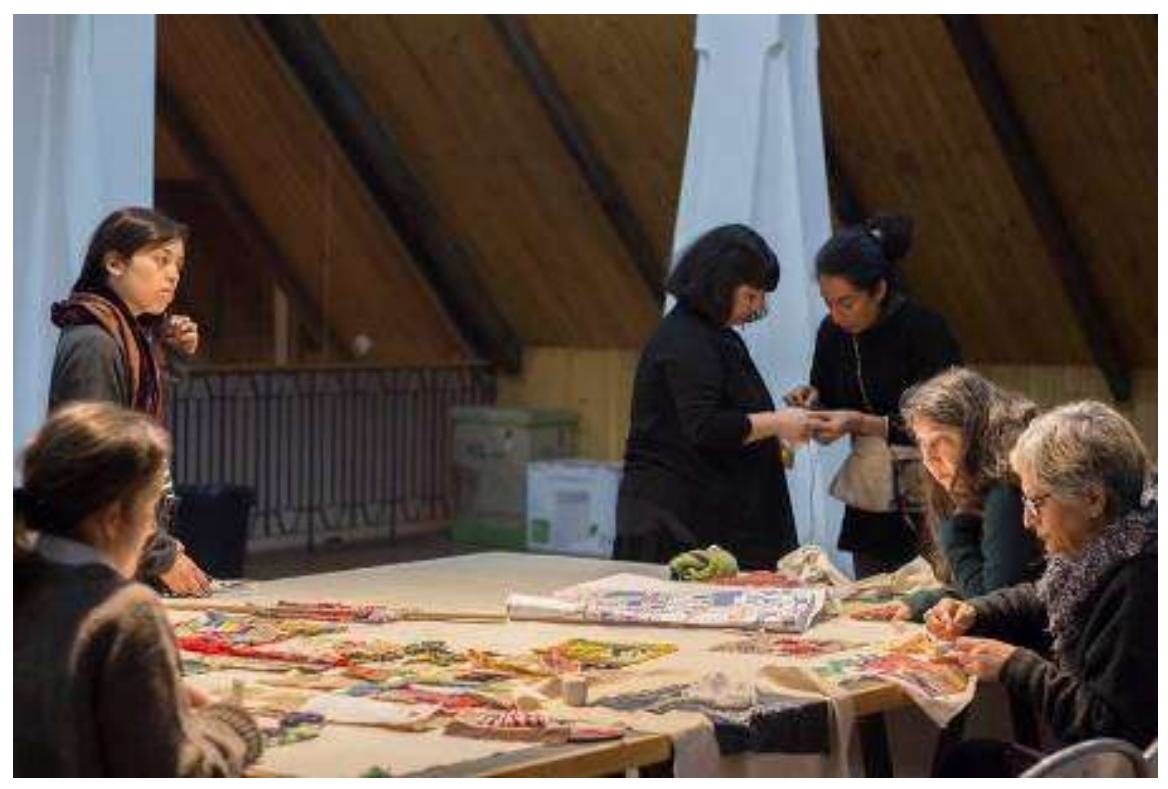

Fig. 4 - Taller de textil comunitario Puntada a puntada: reconstruyendo mi barrio, Museo de la Solidaridad Salvador Allende, 2018.

Poiésis, Niterói, v. 20, n. 33, jan./jun. 2019. 


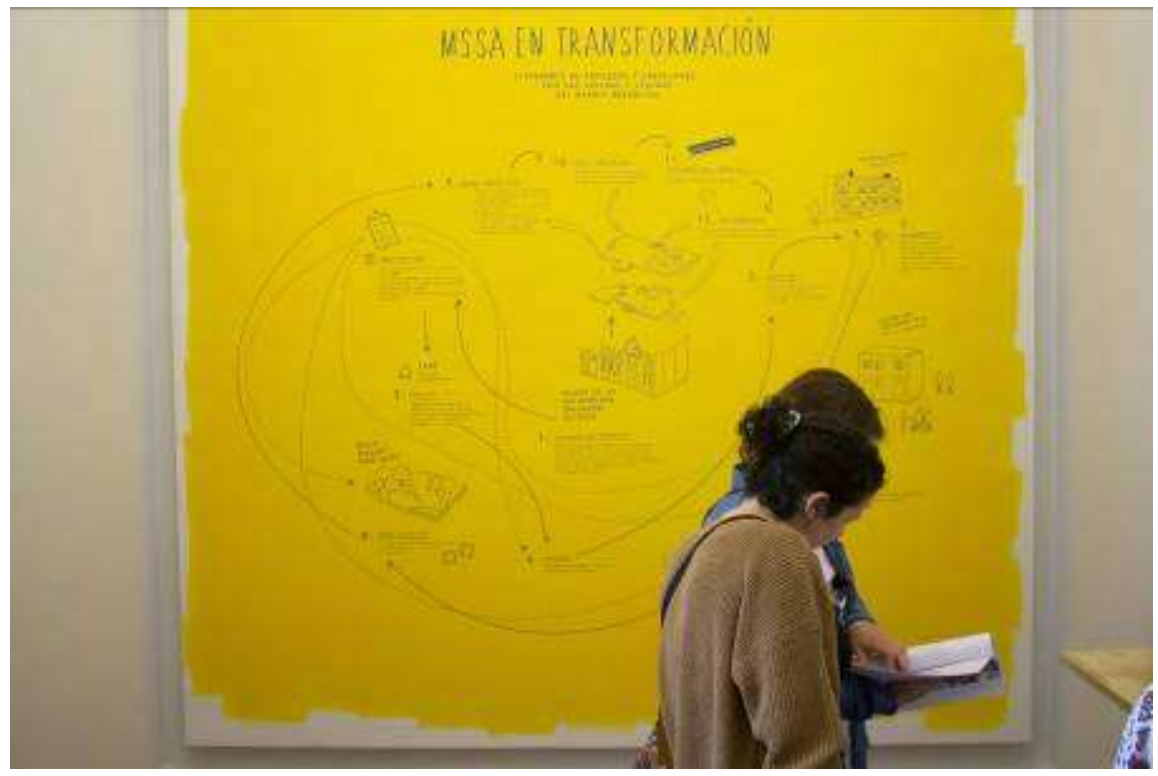

Fig. 5 - Diagrama MSSA en Transformación. Itinerario de procesos y creaciones con las vecinas y vecinos del Barrio República, Exposición Haciendo barrio, Museo de la Solidaridad Salvador Allende, 2018.

Poiésis, Niterói, v. 20, n. 33, jan./jun. 2019. 
nes, profesiones, aficionados al arte y artistas, en su mayoría motivados por juntarse, comentar sus hallazgos, probar con ejercicios y encontrar un lugar de encuentro en las complicidades de un grupo. De manera singular, se relevó en cada taller el aporte - fuera del rigor, la especialización o la formación profesionalizante -, de prácticas intuitivas nutridas por las conversaciones, retroalimentaciones y ejecuciones colaborativas. Este modo permitió, por una parte, generar un flujo de relaciones entre los que poseen conocimientos y aquellos que no, y de desatar la oposición existente entre las prácticas del ocio y la producción del trabajo, para dar paso también a una labor afectiva. Por otra parte, generó discusiones entre artistas, profesionales y aficionados - expresadas tanto en el transcurso de los talleres como en el guion indeterminado de la exposición con observaciones dispares sobre las definiciones de los usos del color, la posición e inclusión de los objetos en el montaje, la revisión de los textos o la difícil tarea de definir un título para la muestra. En esa misma línea y fuera de las convenciones del MSSA, por primera vez se conformó un comité curatorial mixto integrado por el área de Programas Públicos, el área de Programación (exposiciones y museografía) y cuatro vecinos representantes o delegados de cada uno de los talleres, que tuvieron la labor de ser voceros, reunir las opiniones y los acuerdos luego de las votaciones de los distintos participantes. Con los esfuerzos de actuar horizontal y reunir los consensos de muchas personas, la exposición fue llamada Haciendo barrio porque tal como fue escrito colectivamente para la muestra "representa el sentir y el anhelo de toda una comunidad" (Fig. 6).

Es necesario destacar que la aparición de una autoidentificación de una comunidad barrial no fue inmediata, sino que fue incorporándose en los distintos momentos y grados de cercanía, confianza y afectos con las y los vecinos. Esto se fraguó, no solo en un tiempo lento al conocernos, compartir y conversar, sino que sobre todo al debatir, contener y resolver conflictos en un acuerdo común de opiniones y votaciones - sobre todo frente a las exigencias de realizar una exposición. Es en ese proceso de disensos y discrepancias donde se percibieron los momentos de tensión y posterior, flexibilidad, comprensión y acomodo entre las distintas posturas para mantenerse en grupo. Desde esta experiencia, podríamos afirmar que sin conflicto, comunicación y constancia no existe comunidad. 


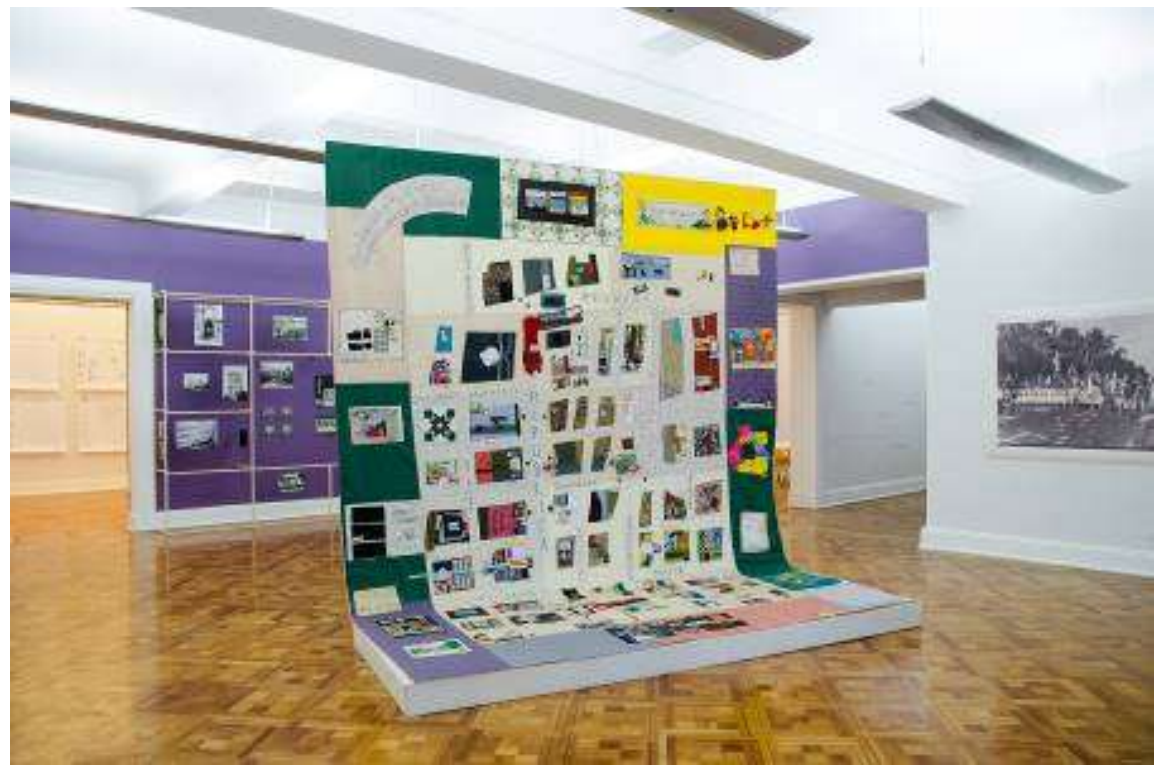

Fiq. 6 - Vista qeneral exposición Haciendo barrio, Museo de la Solidaridad Salvador Allende, 2018.

Poiésis, Niterói, v. 20, n. 33, jan./jun. 2019. 
Tras un mes de inaugurar la exposición en la calle, quisimos volcar la programación del proyecto en una co-planificación entre el equipo de Programas públicos y los vecinos, a partir de sus inquietudes, ideas y propuestas. Los convocamos a una asamblea extraordinaria para reunir sus motivaciones y definir las líneas de aprendizaje que pudieran expandirse en largo plazo dentro de las posibilidades del museo. Con el fin de soltar la imposición de una programación y escuchar en colectivo las opiniones, se llegó a la definición de una agenda denominada más por el oficio que por el tópico. La programación se conformó por tres grupos: textileras, brigada fotográfica y huertoescuela. Este último ha irradiado un campo natural de apertura hacia problemáticas de la ecología social, el cambio climático y los cuidados alimentarios, repercutiendo en una (auto)formación tanto para los vecinos (residentes e institucionales) y el equipo del museo, sobre temas que escapan del canon estético del objeto artístico y que se enlazan más bien a preocupaciones transversales y mundiales sobre destrucción del paisaje natural y la necesidad de reeducarnos desde lo cotidiano y en convivencia con la naturaleza. Huertoescuela y los distintos grupos de textil y fotografía han resignificado los vínculos del equipo del museo con la comunidad en una mutua dinámica constante de aprendizaje y desaprendizaje, de prueba y error, de iniciativas que adquieren otros rumbos que se anidan en el museo pero que adquieren visibilidad fuera de él, en marchas, conciertos, paseos, memoriales y presentaciones. La meta que nos autoimpusimos en un inicio de hacer una exposición en base a las obras de las colecciones quedó por ahora desechada. La importancia radica en la mantención de un lugar de encuentro para aprender en colectivo sobre arte, cultura y cuidados ecológicos.

Entre las fricciones que interrumpen estos procesos, se encuentran varias interrogantes que apelan por una parte a una dimensión temporal: ¿cómo los tiempos de las estructuras y funcionamiento de una institución museal difiere de los tiempos y complicidades de una comunidad? ¿cómo los tiempos y la formación del sistema artístico contrasta y se involucra con la producción ajena al conocimiento concreto, abstracto o la precisión técnica de un oficio? ¿cómo una comunidad vecinal - en donde se incluye el museo como miembro y lugar de encuentro - puede sostenerse en el tiempo? ¿ cómo el museo logra transformar o compatibilizar su función de custodio de una colección junto a las exigencias de 
una comunidad barrial cada vez más activa? Con un cuestionamiento permanente sobre las profundizaciones de la participación colectiva, las expansiones del campo curatorial y pedagógico, estas interrogantes y sus complejidades envuelven hoy los desafíos y transformaciones del MSSA: una infraestructura que logró pasar de ser un mero espacio a una casa-museo, un lugar estimado, cercano y partícipe de una comunidad que se involucra, en su conjunto, en el barrio. Un lugar que incuba y busca ampliarse a una casa de experimentos. 


\section{Notas}

1 Declaración Necesaria. Redactado por el Comité Internacional de Solidaridad Artística por Chile, Santiago, noviembre, 1971 en Museo de la Solidaridad Chile 1971-1973. Donación de los artistas al gobierno popular, Santiago, 2013.

${ }^{2}$ Ejemplo de ello, son los foros realizados en el Instituto de Arte Latinoamericano a partir de 1971 y la exposición Las cuarenta medidas de la Unidad Popular en el Museo de Arte Contemporáneo de la Quinta normal, 1971.

${ }^{3}$ La concepción y gestión de obras donadas al Museo de la Solidaridad fue realizado bajo el alero del Instituto de Arte Latinoamérica de la Facultad de Bellas Artes de la Universidad de Chile, cuyo director fue Miguel Rojas Mix (1934) y quien invita a Mário Pedrosa, forzado al exilio en Chile por las censuras sistemáticas del gobierno brasileño, y a Aldo Pellegrini (1901 - 1973) a participar de cursos, foros y proyectos editoriales de alcance latinoamericano en la Facultad. Los críticos e intelectuales internacionales que integraron el Comité de Solidaridad por Chile (CISAC) tuvieron la tarea de integrar vía donación obras de artistas al museo. Ver: Macchiavello, Un caso de resistencia colectiva: el Museo de la Solidaridad Salvador Allende, 2016.

${ }^{4}$ Actualmente solo en la Avenida República se encuentran más de 10 universidades e institutos técnicos públicos y privados (UCH, UDP, UAB, UDLA, UDL, ILL, IA, IPP, IPCHILE, CIISA, CFT, Instituto de Cultura Helénica, y fundaciones (Educación 2020, Superación de la Pobreza, Corporación Gran Circo Teatro y Boyscouts).

${ }^{5}$ El terremoto de 2010 terminó por destruir algunas de las casonas antiguas teniendo que ser en el peor de los casos, demolidas o en el mejor de los casos, pasar por un lento proceso de reparación (Corporación Arteduca).

6 Una de las iniciativas forjadas por la Municipalidad de Santiago en el 2016 fue la Mesa de cultura barrio República. Con el cambio de la administración del Municipio, la mesa se disolvió. Sin embargo, a partir de octubre de 2017 se retomó el trabajo desde las mismas organizaciones para poder iniciar acciones en conjunto con la Junta de vecinos, Arteduca, la Fundación Superación de la Pobreza, el Comité del Patrimonio del Barrio República y el MSSA. En el 2018, se sumó la Universidad de Los Lagos y la Biblioteca Nicanor Parra de la Universidad de los Lagos.

7 El equipo interdisciplinario de investigación-acción estuvo compuesto por los sociólogos Luis Campos y Tomás Peters, los artistas Rafael Guendelman y Andrés Lima a cargo del documental Mirada de Barrio, el diseñador Rodrigo Dueñas y el área de Programas públicos, conformado por Soledad García (coordinadora), Scarlette Sánchez (productora), Ignacia Biskupovic y Jessica Figueroa (mediadoras).

8 Ignacia Biskupovic (intervención fotográfica), Jessica Figueroa (arte postal), Gabriel Larenas (escritura creativa), María Paz Morales (publicaciones experimentales) y Daniela Pizarro (-textil comunitario). 


\section{Referencias}

ANDONIE, Carolina. Nace un Barrio Universitario. El Mercurio, viernes 6 de junio, 2003.

BIANCHI, Soledad. Los que tuvimos un día la capacidad de asombrarse. Poesía de los años $60 . .$. y algo más. In Libro de Lectura(s). Poesías, poetas y poéticas. Santiago do Chile: Editoral USACH, 2013.

DE LA MAZA, Gonzalo. Construcción democrática, participación ciudadana y políticas públicas en Chile, Tesis doctoral, 2010.

DELISS, Clementine. Curating Neighborhoods: Manifesto for the Post-Ethnographic Museum. Modern Painters, v. 26, i. 8, p. 34-35, 2014.

DEWEY, John. Democracia y Educación. Madri: Ediciones Morata, 1998.

FERREIRA, Gloria, HeRkenhOfF, Paulo. Mário Pedrosa Primary Documents. Nova York: The Museum of Modern Art, 2015.

GARCÉS, Marina. Un mundo común. Barcelona: Ediciones Bellaterra, 2013.

MACHIAVELLO, Carla. Un caso de resistencia colectiva: el Museo de la Solidaridad Salvador Allende. In A los artistas del Mundo. Cidade do México: Museo Universitario de Arte contemporáneo, 2016.

MÁRQUEZ, Francisca. Historias e identidades barriales del Gran Santiago: 1950-2000. IX Congreso Argentino de Antropología Social Misiones, agosto de 2008. [Esta ponencia reflexiona sobre resultados del Proyecto Fondecyt No 1050031, dirigido por la autora entre los años 2005-2008].

MÖRSCH, C.; SACHS, A.; SIEBER, T. (Ed.). Contemporary Curating and Museum Education. Blielefeld: Verlag, 2017.

PEDROSA, Mário. El modelo del socialismo chileno y el Frente del Arte. In PEDROSA, Mário. De la naturaleza afectiva de la forma. Madri: Museo Nacional Centro de Arte Reina Sofía, 2017.

ZALDÍVAR, Claudia (Ed.), Museo de la Solidaridad Chile 1971-1973. Donación de los artistas al gobierno popular. Santiago do Chile: MSSA, 2013.

Poiésis, Niterói, v. 20, n. 33, jan./jun. 2019. 